\title{
TECENDO MEMÓRIAS EDUCACIONAIS NO SERTÃO PARAÍBANO: CARMELITA GONÇALVES E SUAS CONTRIBUIÇÕES À EDUCAÇÃO EM CAJAZEIRAS/PB
}

Débia Suênia da Silva Sousa

\section{RESUMO:}

O presente artigo tem como objetivo enfocar a contribuição da professora Carmelita Gonçalves no processo educacional e cultural da cidade de Cajazeiras. A escolha pela referida educadora encontra justificativa na sua dedicação ao ensino, a contar desde o final dos anos 40 do século passado até os dias atuais, bem como da inevitável importância de divulgar sua história e suas contribuições nos processos educacionais junto ao Colégio Nossa Senhora do Carmo, conhecido como Colégio de Carmelita. Pretender desvelar à sua história corresponde também conhecer as suas representações religiosas, educacionais e culturais na interface de suas práticas educativas. A pesquisa busca apoio metodológico nas contribuições evidenciadas pela Nova História Cultural, que alargam o conceito de fonte, possibilitando o desvelamento de objetos e sujeitos no processo histórico cultural, até então inusitados. A princípio, utilizam-se fontes escritas impressas, do Patria Jornal, dentre outras revistas locais, e fontes orais, através de entrevistas. Por se tratar de uma pesquisa em andamento, ainda não há verificação de resultados, porém, existe a possibilidade de revelar a memória dos processos educacionais, na figura da educadora Carmelita Gonçalves, bem como as práticas culturais e sociais ofuscadas pelo tempo, a história da configuração social em destaque: Cajazeiras.

Palavras-chave: Educação cajazeirense. Carmelita Gonçalves. Representações. Memórias

\section{WEAVING MEMORIES EDUCATIONAL IN SERTÃO PARAIBANO: CARMELITA GONÇALVES AND HER CONTRIBUTIONS TO EDUCATION IN CAJAZEIRAS/PB}

\begin{abstract}
:
The present article has as objective focuses teacher Carmelita Gonçalves' contribution in the educational and cultural process of the city of Cajazeiras. The choice for the referred educator finds justification in your dedication to the teaching, to count from the end of the forties of the century passed to the current days, as well as of the inevitable importance of publishing your history and your contributions close to in the educational processes Our Colégio Senhora of Carmo, known as School of Carmelita. To intend to watch to your history also corresponds to know your representations religious, educational and cultural in the interface of your educational practices. The research looks for methodological support in the contributions evidenced by the New Cultural History, that they enlarge the source concept, making possible the desvelamento of objects and subjects in the cultural historical process, until then unusual. At first, written sources are used printed, of the Pátria Jornal, among other local magazines, and oral sources, through interviews. For treating in process of a research, there still is not verification of results, however, the possibility exists of revealing the memory of the educational processes, in the educator's Carmelita Gonçalves Keywords: Education cajazeirense. Carmelita Gonçalves. Representations. Memoirs
\end{abstract}




\section{Introdução}

A idéia de desenvolver este estudo para enfocar a contribuição da professora Carmelita Gonçalves no processo educacional e cultural de Cajazeiras/ PB encontra justificativa na dedicação da referida educadora ao ensino em Cajazeiras, a contar desde os anos 40 do século passado até os dias atuais, bem como da inevitável importância de divulgar sua história e suas contribuições nos processos educacionais do Colégio Nossa Senhora do Carmo, conhecido como Colégio de Carmelita.

Final dos anos 40 e início dos 50 do século passado se mostram importantes como ponto de partida, uma vez que, nessa época, é notável o desenvolvimento social, religioso, político, cultural e educacional na cidade de Cajazeiras, Paraíba, mais conhecida como a Terra do Padre Rolim.

Dentre estes acontecimentos, pode-se destacar, a fundação da Viação Gaivota, com itinerário João Pessoa Cajazeiras no ano de 1954; A institucionalização da data de nascimento de Padre Rolim como o Dia da Cidade no ano de 1948; A fundação do Colégio Nossa Senhora do Carmo, em 1943; A direção do Colégio Diocesano Padre Rolim aos padres Salesianos em 1939, em 1943 é comemorado o ano Centenário do Colégio Diocesano Padre Rolim, celebrado com muitas festividades; Conferência sobre a vida e obra de Padre Rolim, no Cine-Teatro Éden, no ano de 1943; A efervescência cultural em 1953, com o surgimento do TAC - Teatro de Amadores de Cajazeiras, e o jornal, o Tribuna do Sertão; Ainda em 1953, três cajazeirenses são destaques no cenário nacional e internacional, Ivan Bichara é o Presidente da Assembléia Legislativa; Dr. João Guimarães é o Secretário de Fincas do Estado e Zé do Norte, com sua música e seu folclore, brilha no Festival de Cannes na França; Dom Zacarias Rolim de Moura é o novo Bispo de Cajazeiras, no ano de 1953; Padre Américo Sérgio Maia, vigário paroquial, e redator-chefe do Jornal Correio do Sertão, no ano de 1953; A imagem peregrina de Fátima chega a Cajazeiras nesse ano, confirmando a vocação cultural de religiosa da Terra de Mãe Aninha (a mãe de Padre Rolim); A vereadora Rita de Cássia Assis da União Democrática Nacional $(\mathrm{UDN})^{1}$, chega a Câmara Municipal na defesa das mulheres cajazeirenses.

É nesse cenário de novas perspectivas sociais, culturais, religiosas e educacionais que à história de Carmelita Gonçalves, enquanto educadora vai se desenvolvendo. Portanto, pretender desvelar a história de Carmelita Gonçalves corresponde também conhecer as suas representações religiosas, educacionais e culturais na interface de suas práticas educativas.

A pesquisa busca apoio metodológico nas contribuições evidenciadas pela Nova História Cultural, que alargam o conceito de fonte, possibilitando o desvelamento de novos objetos e sujeitos no processo histórico cultural, até então inusitados, silenciados ou desconsiderados para a construção da história; neste caso específico, trazer à luz a história da professora Carmelita Gonçalves é uma tentativa de contribuir não só para a construção da história das mulheres, mas também para a história da educação na Paraíba.

O estudo desenvolve-se no campo histórico-biográfico, ou seja, buscando emergir no "[...] conjunto de preocupações as memórias coletivas ou individuais [...] como uma grande força que pouco a pouco possibilitam nos compreendermos melhor enquanto homens e mulheres de nosso tempo" (PINHEIRO; ANANIAS, 2009. p. 09). Nessa perspectiva, o estudo em andamento organiza-se por meio de escritos e depoimentos (estes revelados nas de entrevistas, no qual os entrevistados são identificados por seus nomes 
verdadeiros com consentimento para publicação) relevantes sobre a vida pública de Carmelita Gonçalves.

\section{Carmelita Gonçalves: uma vida de dedicação ao ensino}

Originária de uma família abastarda, Carmelita Gonçalves nasceu em 22 de julho de 1924, no Sítio Barra do Catolé, município de Cajazeiras, estado da Paraíba, filha do Coronel Manoel Gonçalves Dias e Hortência Gonçalves. Desde criança, tinha interesse de entrar para ordem dos Carmelitas Descalços, mas por fatalidade, após a morte de seu pai, o rumo de sua vida é modificado. Forçada pelas circunstâncias, fica em Cajazeiras, ajudando na criação dos seus irmãos. Nunca se casou, hoje vive em sua casa e também no seu Colégio na companhia de seus familiares. Ao concluir o Curso Normal em 1943, no Colégio Nossa Senhora de Lourdes, funda nesse mesmo ano a Escola Nossa Senhora do Carmo, passando a Colégio no ano de 1986.

Assim, desde 1943 até os dias atuais, Carmelita Gonçalves está a frente da educação desenvolvida no Colégio Nossa Senhora do Carmo, com funções distintas, a saber: professora de língua portuguesa e diretora. Nesse sentido, pode-se dizer que conseguiu desde cedo ultrapassar os limites impostos à mulher no campo educacional, pois sabe-se que historicamente existe um vínculo e uma certa naturalização do espaço da sala de aula como apropriado para a mulher, o mesmo não acontecendo com o cargo de gestor, que predominantemente esteve nas mãos dos homens, embora esse quadro venha sofrendo alteração nos tempos mais recentes. Todavia, deve-se assinalar que a professora Carmelita detinha uma condição favorável a essa ruptura: recursos para abrir sua própria escola. E pelo êxito que sua instituição tem logrado ao longo desses anos, pode-se dizer que detém também as características necessárias a uma boa gestora.

O Colégio Nossa Senhora do Carmo, continua sendo referência na educação cajazeirense, uma vez, que hoje, se alargou o número de escolas e colégios na cidade. Quando o mesmo surgiu os colégios que se destacavam era o Colégio Diocesano de Padre Rolim e o Colégio Nossa Senhora do Carmo, na rede privada de Ensino, na rede pública era o Colégio Polivalente, Colégio Estadual e o Colégio Dom Moisés Coelho. Sabe-se que nos dias atuais, o Colégio Diocesano de Padre Rolim não existe mais, outros Colégios da rede privada atuam na cidade como, por exemplo, o Colégio e Curso Definição GEO, o Colégio Alternativo Máster, dentre outros, mas, mesmo com toda expansão de colégios e escolas o Colégio de Carmelita se destaca. Quando chega alguma família nova, na cidade, ao procurarem o melhor lugar para matricularem seus filhos, o Colégio de Tia Carmelita é indicado por sua dedicação ao ensino em Cajazeiras por mais de seis décadas. É visível o destaque do Colégio na representação dos entrevistados: “[...] atualmente o Colégio está em construção de novas salas de aula, laboratórios e praça de alimentação". (ENTREVISTADO DULCÍLIO ELIAS RAMOS).

A educação, no Colégio Nossa Senhora do Carmo, sob a autoridade de "Tia Carmelita", tem uma dimensão que se estabelece na vida profissional dos que lá estudaram, por meio de um ensinamento religioso metódico, que acompanha o cotidiano das atividades desenvolvidas no referido colégio. Acerca dessa representação, a jornalista Cristina Moura destaca:

Não posso apagar o que senti na Escola Nossa Senhora do Carmo. Foi uma década, uma estrada uma fonte. Cada oração antes da aula, ainda me acompanha. Cada canção para receber na alma um dia feliz está comigo, impressa como uma revista que está longe de ser esta. Não 
possui assinantes nem anunciantes. O coração suspeito é quem ler. (MOURA, 2003. p. 34)

O que se sabe, é que a característica de evangelizadora da professora Carmelita Gonçalves transcende os muros do Colégio Nossa Senhora do Carmo, uma vez que esta se dedica, também, a um trabalho voluntário na construção de capelas na zona rural de Cajazeiras, além de ser uma das grandes colaboradoras do Seminário Nossa Senhora da Assunção, desde o ano de 1956. Ou seja,

Ela sempre foi uma grande colaboradora desse Seminário até os dias de hoje. Não gosta de aparecer naquilo que faz em favor dos outros. É uma pessoa muito humilde. A sua casa sempre foi um pequeno seminário, porque ajudava e continua ajudando na formação dos padres e conservação daquele educandário. (ENTREVISTADO DULCÍLIO ELIAS RAMOS).

Quando se trata da dedicação da professora Carmelita ao ensino, o que se pode destacar, entre os primeiros depoimentos que se tem para esse momento do trabalho, é a sua dedicação à educação em Cajazeiras, por meio do processo educacional desenvolvido no Colégio Nossa Senhora do Carmo. A respeito desse reconhecimento, o depoimento do seu amigo Dulcílio Elias Ramos se apresenta oportuno:

O campo da educação é fundamental na vida desta grande educadora, pois é uma apaixonada pelo ensino. Muitas gerações já passaram pelo Colégio Nossa Senhora do Carmo. Muitos dos seus ex-alunos brilham em sua vida profissional por esse Brasil afora. Aos 85 anos continua firme e forte como Diretora desse seu Colégio que é uma referência em muitas cidades paraibanas, cearenses e riograndenses. (ENTREVISTADO DULCÍLIO ELIAS RAMOS).

Mesmo com o silêncio que é peculiar a esta educadora, ao tratar de sua contribuição à educação em Cajazeiras, a mesma, "[...] continua sendo uma voz de vanguarda, testemunha do seu tempo e faz do seu silêncio discurso público um instrumento de denúncia, mostrando que é possível se fazer o melhor em qualquer situação". (ALBUQUERQUE, 2000. p. A5 ). Pela firmeza e dedicação em dirigir o Colégio Nossa Senhora do Carmo, é que a biografia da professora Carmelita Gonçalves se consolida como um projeto de fundamental importância na conjuntura educacional da cidade de Cajazeiras, uma vez que " [...] ela merece que o futuro de vários futuros saiba o que ela representa. Até hoje, ninguém sabe se ela é mestra, se é mãe, se é tia, se é amiga. Ela faz questão de ser ela mesma e isto é o mais importante, creio". (MOURA, 2003. p. 34).

Assim, ver-se que a representação que se tem da educadora Carmelita Gonçalves é de uma mulher forte, autêntica, guerreira. No trecho acima, além do destaque dado ao papel de educadora, são atribuídas outras funções: mãe, tia, amiga, como se fossem funções sinônimas, numa aproximação dos espaços da casa e da escola, que pode amenizar as diferenças as diferenças entre os mesmos.

Contudo, mesmo a sua revelia Carmelita é sempre homenageada pela sociedade cajazeirense, ora destacada como personalidade marcante no âmbito educacional desde os anos 50 do século XX, como bem destaca o Pátria Jornal (2003); ora por singelos 
reconhecimentos, como a placa que uma família cajazeirense, em outubro de 2004, lhe presenteou e, que se encontra na sala de entrada do Colégio Nossa Senhora do Carmo, como se pode observar na fotografia que segue:

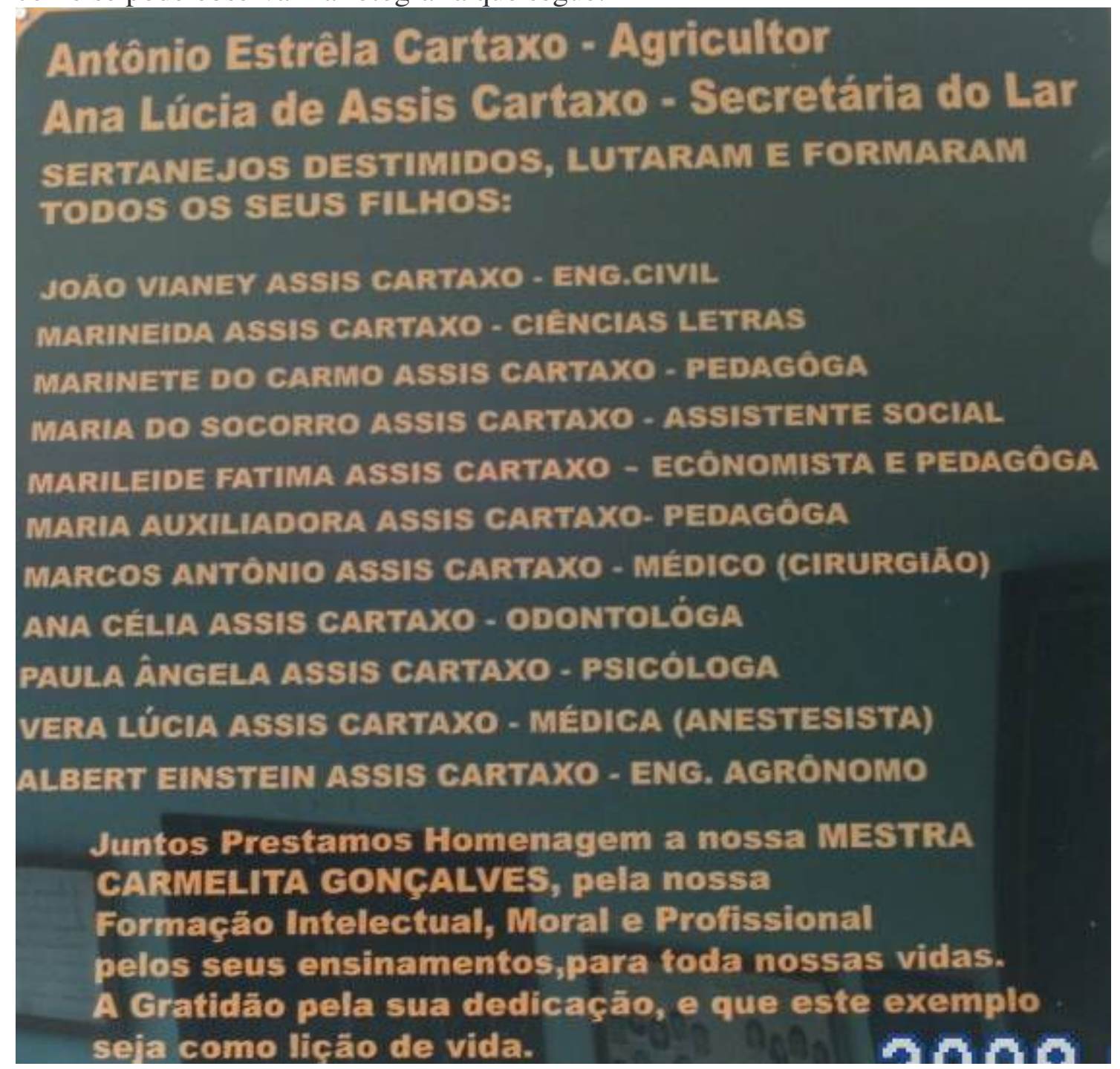

Placa de Homenagem à professora Carmelita Gonçalves.

Fonte: acervo pessoal de Débia Suênia da Silva Sousa. Cajazeiras/PB (2009).

Assim, é possível afirmar que a sua escola outrora, hoje colégio, educou e educa gerações; é considerada como uma referência para educação em Cajazeiras. A representação que muitos ex-alunos têm de Carmelita é bastante significativa. Dentre as filhas do casal, Antônio Estrela Cartaxo e Ana Lúcia de Assis Cartaxo, que prestaram uma homenagem à educadora, por meio de uma placa como símbolo de gratidão pela presença desta na educação dos seus onze filhos, a sétima filha destes revela que, "[...] nos sentimos felizes, orgulhosos da contribuição e influência desta maravilhosa mulher na nossa formação pessoal e intelectual" (ENTREVISTADA ANA CÉLIA ASSIS CARTAXO). Portanto, "Carmelita, sempre foi e continua sendo a inspiração daqueles que desejam abraçar o caminho ingrato e irreconhecido do magistério. Fez e continua fazendo a história educacional do Sertão da Paraíba.” (ALBUQUERQUE, 2000. p. A5 ).

Considerada como referência educacional no Sertão paraibano, precisamente, na cidade de Cajazeiras, Carmelita era, e ainda é, defensora de uma educação tradicional, disciplinada por valores morais e religiosos. Nesse sentido, a jornalista Cristina Moura, ex- 
aluna da professora Carmelita, em um dos seus artigos publicados no Gazeta do Alto Piranhas, de 22 de agosto de 2007, afirma que o dia escolar no Colégio Nossa Senhora do Carmo seguia sempre o mesmo ritual:

Ao chegar à escola, um doce e meditativo início de cotidiano: desejar bom dia a todos os que se cruzassem pelo caminho, ouvir a solene palestra de Tia Carmelita, rezar um Pai Nosso e uma Ave Maria. Tudo isso compreendia respeito, obediência, amizade dedicação. (MOURA, 2007, p. 3)

O ensino para Carmelita é um processo rigoroso, disciplinado, sobretudo, quando se trata da língua portuguesa. A educadora tem orgulho em dizer que os alunos que passaram por suas mãos sabem escrever corretamente. Ela preza tanto a disciplina que desde o início de sua prática docente e, como mestra regente do Colégio Nossa Senhora do Carmo, é comum interromper a aula de outro professor, sempre que presencia(va) momentos de indisciplina, visando fazer com que suas lições cheguem até os corações e as mentes do seu alunado. Acerca desse comportamento metódico, Moura (2007, p. 3) afirma: "[...] de repente, no meio da aula, a mestra chegava com uma fábula, uma história, um aconselhamento, um sincopado pedido de silêncio com o psh... sh... sh...". Esses ensinamentos morais, disciplinadores são apreendidos e aprendidos pelos alunos de forma contínua e processual, ou seja, à medida que vão,

[...] experimentando a diferença entre bem e mal. Quem nunca colou na prova? Nem uma olhadinha, nem uma simples espiada, nenhum papel jogado no chão por acaso? Duvido. Mas, caso acontecesse o flagra, seria, no mínimo, uma semana de sermões. A cola era a simbologia da desonestidade. [...] sabíamos disso. Citações bíblicas faziam parte do processo. A preparação para a primeira eucaristia também. (MOURA, 2007. p. 3).

Segundo estas informações, é cabível afirmar que a religiosidade da educadora Carmelita Gonçalves está evidenciada a todo tempo na sua prática docente, bem como na concepção de educação que defende para o seu estabelecimento de ensino. Segundo a exaluna Cristina Moura, tanta disciplina no processo educacional do Colégio Nossa Senhora do Carmo reflete numa aprendizagem que ultrapassa as atividades de "decoreba". Essa perspectiva é evidenciada em sua crônica dedicada à mestra:

Todo o aparato humanístico, nos fazia entender como era mais fácil seguir o caminho da retidão, do amor ao próximo a essência cristã. [...]. Os resultados podem ser apreendidos hoje mesmo, dentro de cada um. Aposto com quem quiser. Lá, a malemolência não tinha vez ou lugar. O negócio era manter-se firme, em atividade, decidido a aprender, a não brigar, a ser gentil e educado. E a mestra com aquela frase habitual, para que jamais esquecêssemos, [...]. A preguiça é a chave da pobreza. (MOURA, 2007. p. 3). 
Ainda na opinião dessa ex-aluna, a disciplina empregada no ato de educar da professora Carmelita não deve ser entendida unicamente como um mecanismo de controle que causa medo aos educandos. Estes vão aprendendo a aprender, envolvidos num processo muitas vezes de devoção, mas que também não deixa de levar em consideração aspectos lógicos e cognitivos do ser em construção.

Vivíamos naquela espécie de reverência a mestra. Não, não tínhamos medo. Não era medo. Era uma devoção misturada a um poço de razão. Nossa lógica funcionava muito bem: não gostaríamos de ser surpreendidos com uma suspensão ou uma carta de advertência aos pais. [...] Era uma overdose disciplinar que nos convencia e nos encantava, a cada compasso do lugar, com gente de diversas linhas da sociedade. Por que será que políticos, homens do poder, candidatos e outros aspirantes ao estrelato iam sempre fazer uma visita à mestra? [...] Nós, os coleguinhas, com ruindade ou bondade, sabemos o quanto foi árdua e gostosa tanta disciplina, tanta oração. (MOURA, 2007. p. 3).

Mesmo sendo professora de língua portuguesa e, vale salientar, bastante exigente, o que Carmelita mais gosta de fazer como educadora é orientar os estudantes nas suas vivências enquanto pessoa mediante de lições que lhes sirvam para a vida toda. A respeito dessa perspectiva, a ex-aluna Josiane Dantas Martins de Lucena revela que:

Em algumas oportunidades ela mostrou como deveríamos reger nossas vidas, e não esquecendo da idade que tínhamos, fez isso de uma forma bem simples, indagando-nos de como começaríamos a construir uma casa. [...] ela disse que antes de começar a construir uma casa deveríamos planejar a sua construção, em seguida fazer a base e daí por diante fazer paredes portas, janelas e, por fim o telhado. E o mais interessante que mesmo com pouca idade que eu tinha, por volta de 5 anos de idade, não esqueci dessa conversa. [...] foi um aprendizado que carrego por toda a minha vida. E sempre que quero começar a fazer algo, lembro desse ensinamento e, o considero de grande contribuição na minha vida. (ENTREVISTADA JOSIANE DANTAS MARTINS DE LUCENA).

Carmelita Gonçalves se faz notar na sua prática educacional, por vários aspectos sob as lentes dos seus alunos, sempre pelo costume de pedir silêncio, como "oração constante", pelo modo de se vestir, pelos seus óculos, como mostra a fotografia que segue: 


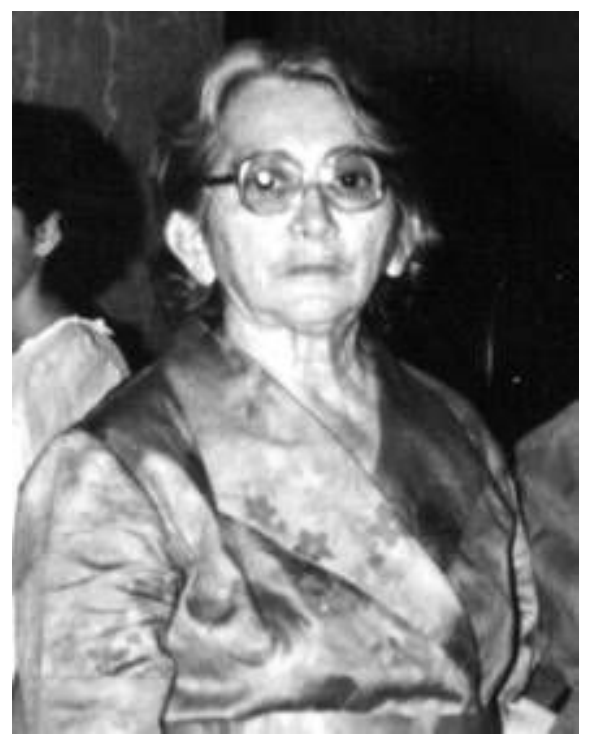

Carmelita Gonçalves

Fonte: acervo Gazeta do Alto Piranhas/ sem data

Enfim, Carmelita se faz notar pelos seus hábitos, “[...] assistíamos aos gostos dela: sempre muito café e muito caldo de mocotó, dois óculos com armações bem diferentes, um apelido para cada aluno, distanciamento a homenagens". (MOURA, 2007. p. 3).

Não se pode deixar de aludir que apesar de todas as propostas de renovação educacional, como por exemplo, a educação libertadora difundida por Paulo Freire a partir dos anos 80 do século XX, da concepção de educação construtivista, representada, quiçá como a proposição mais elaborada da Pedagogia do século XX, o ensino defendido pela professora Carmelita Gonçalves é tradicional, conservador. Com isto, não queremos estabelecer um juízo de valor, até porque nas falas e textos que trouxemos até aqui, as exalunas da escola e/ou da citada professora consideram apropriados os procedimentos da mesma. Todavia uma dessas ex-alunas do Colégio Nossa Senhora do Carmo, Josiane Dantas Martins de Lucena, que aí estudou entre os anos de 1983 e 1986, em um trecho de sua entrevista destaca como a rigidez da professora poderia causar temor:

Apesar dela nunca ter sido minha professora, algumas vezes substituía a professora titular da minha sala e, se mostrava muito rígida e enérgica e às vezes até agressiva. Esses momentos de agressão foram marcantes, mesmo que não fossem comigo, eu ficava apavorada quando via ela puxar nas duas orelhas dos meninos de uma só vez. Essas atitudes de Carmelita Gonçalves provocavam em mim e, na maioria das crianças, o medo de errar, isso não era admitido por ela, tudo deveria acontecer absolutamente como ela determinava. [...] Apesar da rigidez enérgica e as regras até carrasca, Carmelita Gonçalves soube e, ainda, sabe impor limites e, educar, algo tão difícil na atualidade. (ENTREVISTADA JOSIANE DANTAS MARTINS DE LUCENA).

A entrevistada, apesar de destacar que a rigidez da professora a assustava, bem como aos colegas, com a utilização de castigos corporais, - prática que junto com o uso da 
palmatória esteve em vigor durante bastante tempo - acaba por apontar como algo positivo a imposição de limites que marca a prática educativa da referida mestra.

Não se pode negar a força que Carmelita Gonçalves tem. É um poder influenciador muito enérgico, no qual o erro não é permitido, assim a representação que os ex-alunos têm da educadora é sempre de uma mulher determinada, que sabe como educar, que sabe o que faz.

Muitos sentem-se felizes em poder fazer algum tipo de homenagem à educadora que tanto contribuiu na educação de muitas gerações na cidade de Cajazeiras. É o que se pode perceber no depoimento que segue:

Tecer comentários sobre a professora Carmelita Gonçalves me enche de glórias. São muitos adjetivos pertinentes à mesma: uma mulher sertaneja, guerreira, destemida com um coração humilde, enorme que desde muito cedo vem contribuindo com a educação das gerações cajazeirenses espalhadas pelo Brasil afora. (ENTREVISTADA ANA CÉLIA ASSIS CARTAXO).

Mais uma vez se vê reforçado o reconhecimento da importância da educadora Carmelita Gonçalves na interface da educação cajazeirense. Ou seja, fica evidente que Carmelita educou gerações que estão espalhadas pelo Brasil, e a maioria dos seus exalunos se destacam profissionalmente e, atribuem o sucesso vivenciado ao método educacional tradicional que a mesma defende. Ou seja,

A sua missão aqui está sendo bem desempenhada, com uma profissão árdua que encontra referência e intervenção do nosso Senhor Deus, para que a mesma possa continuar exercendo suas atividades nos dias atuais, onde se depara com jovens tão diversificados e perturbados que não sabem dar o valor que ela merece, pois a professora Carmelita é referência na nossa cidade. Muitos são os seus ex-alunos que se destacam profissionalmente no Brasil, como vi recentemente destacados na edição de agosto do Gazeta do Alto Piranhas, pessoas que estudaram no Colégio de Carmelita, como por exemplo: Francisco Leydson Formiga Feitosa, médico veterinário, professor adjunto da UNESP; Halane Maria Braga Fernandes, engenheira civil, professora adjunta I da UFRSA; Carlos Alberto Montenegro, que é diretor administrativo da agência MULTISERVICE, também Leure Amaral Rolim, que é funcionário público da SUDEMA, dentre outros cajazeirenses. (ENTREVISTADA ANA CÉLIA ASSIS CARTAXO).

Portanto, pode-se perceber que para muitos a metodologia de ensino desenvolvida por Carmelita e, por conseguinte, no Colégio Nossa Senhora do Carmo, é reconhecida como sinônimo de sucesso, de progresso. O depoimento a seguir expressa muito bem essa representação:

[...] torna-se bastante gratificante, para os que reconhecem as suas metas, os dons que ela tem no ato de ser professora, ela fica 
lembrada como um amor de mãe. Mãe que sabe educar e tomar as medidas certas para nos conduzir no bom caminho, no caminho do sucesso. (ENTREVISTADA ANA CÉLIA ASSIS CARTAXO).

A singularidade que se percebe no relato acima, sobre a professora em destaque, emerge de relações básicas e complexas a respeito da maneira como esta desempenha a sua profissão de educadora, proprietária e diretora do Colégio Nossa Senhora do Carmo.

\section{Considerações finais}

$\mathrm{Na}$ verdade a pretensão aqui anunciada seria da descrição da história de vida da professora Carmelita Gonçalves frente ao seu trabalho desenvolvido no Colégio Nossa Senhora do Carmo e como este tem repercussão na história da Educação em Cajazeiras. Por se tratar de uma pesquisa em andamento, ainda, não se tem informações suficientes para alcançar o objetivo proposto.

No entanto, é possível afirmar que Carmelita desde o inicio dos anos 40 do século XX lutou e luta pela educação na cidade de Cajazeiras. A sua dedicação às atividades educacionais desenvolvidas no Colégio Nossa Senhora do Carmo dividem o tempo com um grande envolvimento com as atividades religiosas. Não é a toa que se percebe uma influência significativa da religiosidade na sua metodologia de ensino, na sua prática educacional à frente do Colégio Nossa Senhora do Carmo.

É possível dizer que Carmelita é representada na cidade de Cajazeiras como uma mulher guerreira, muitas vezes rude na maneira de educar, mas que acaba sempre sendo reconhecida. O que a torna respeitada é a sua autenticidade, com seu jeito de se vestir, de se comportar e sua humildade, aspectos revelados nos depoimentos aqui elencados.

Os momentos que ex-aluna(o)s passaram no Colégio podem ser compreendidos como algo que faz parte da história dela(e)s, ou seja, a história do Colégio de Carmelita, também é dela(e)s. A rigidez, marca da educadora, é algo que se mostra sempre relembrado pelos estudantes que vivenciaram a educação no seu colégio, como um ensinamento de vida. Portanto, Carmelita não é apenas considerada a melhor professora de língua portuguesa, que exige que os estudantes aprendam; na sua pedagogia própria, ela também orienta os estudantes com lições de vida.

\section{Referências}

ALBUQUERQUE, José Antonio de. Carmelita Gonçalves: a saga de uma Paixão. In: Gazeta do Alto Piranhas. Ano II, n. 95, Cajazeiras, 15 a 21 de outubro de 2000.

MOURA, Cristina, Carmelita Gonçalves. In: Gazeta do Alto Piranhas. Ano IX, n. 454, Cajazeiras, 22 de agosto de 2007.

Tia Carmelita de verdade. In: Oba. Ano 2, n. 14, Cajazeiras, 2003.

PINHEIRO, Antonio Carlos Ferreira; ANANIAS, Mauricéia. Histórias, memórias e políticas educacionais: relações possíveis na contemporaneidade. In: PINHEIRO, Antonio Carlos Ferreira; ANANIAS (Orgs). Educação, direitos humanos e inclusão social: 
histórias, memórias e políticas educacionais. João Pessoa: Editora Universitária da UFPB, 2009.

REVISTA PATRIAJORNAL, Edição histórica alusiva aos 80 anos. Cajazeiras: Gráfica Real, 22 de agosto de 2003.

\section{Fontes Orais}

Dulcílio Elias Ramos. Amigo de Carmelita Gonçalves. Entrevista concedida em 07/09/09. Ana Célia Assis Cartaxo. Ex-aluna de Carmelita Gonçalves. Entrevista concedida em 12/09/09.

Josiane Dantas Martins de Lucena. Ex-aluna de Carmelita Gonçalves. Entrevista concedida em 30/08/2009

Notas:

\footnotetext{
${ }^{1}$ As informações aqui apresentadas acerca da efervescência cultural, social, cultural e política da cidade da Cajazeiras, no período compreendido entre o final dos anos 30, início dos anos 40 e a década de 50 a edição de 22 de agosto de 2003 do Pátria Jornal.
}

Artigo recebido em: 12/04/2010

Aprovado em: 7/5/2010 